\title{
Comparative study of a simulative bearing design with an experimentally determined data of a prototype bearing
}

\author{
Margarita Mármol Fernández ${ }^{1}$ (D) Lukas Rüth ${ }^{1}$ Bernd Sauer ${ }^{1}$ (D)
}

Received: 1 March 2021 / Accepted: 10 May 2021 / Published online: 9 June 2021

(c) The Author(s) 2021

\begin{abstract}
In some specific applications, the need of an optimized rolling bearing, having a similar load carrying capacity as a tapered roller bearing but with much lower friction losses is still to be addressed. In this paper, a new model is developed using a multibody simulation software and its experimental validation is presented.

After studying many different (in use and only patented) roller geometries and based on an existing and already validated model for tapered roller bearings, a new model has been created changing the basis of its geometry. When the rolling bearing is highly loaded, the new geometry will show lower friction losses than a conventional tapered roller bearing. In order to confirm this premise, as well as to validate the model, a prototype of the new optimized geometry has been manufactured and experimentally tested, together with a tapered roller bearing of same main dimensions. The tests have taken place in a frictional torque test rig, where it is possible to realistically reproduce the loads and misalignments occurring on a bearing.

The results of these tests together with its comparisons with the results of the multibody simulation models are discussed here. It has been observed, that the new model not only can be validated, but also presents less friction losses than the ones obtained when using a tapered roller bearing under some operating points with highly loaded bearings.
\end{abstract}

\section{Simulative Lagerauslegung im Vergleich zu experimentell ermittelten Daten an einem Prototyplager}

\section{Zusammenfassung}

In einigen spezifischen Anwendungen, wird noch nach optimierten Wälzlagern, mit ähnlicher Tragfähigkeit jedoch viel geringeren Reibungsverlusten, wie sie in Kegelrollenlagern vorkommen gesucht. In diesem Artikel wird ein neues Modell vorgestellt, das mit einer Mehrkörpersimulationssoftware erstellt wurde und die Ergebnisse der experimentellen Validierung werden präsentiert.

Nach der Untersuchung vieler verschiedener (existierender und nur patentierter) Rollengeometrien und basierend auf einem vorhandenen und bereits validierten Modell für Kegelrollenlager, wurde mit den entsprechenden Änderungen an die Geometrie, ein neues Modell erstellt. Wenn das Lager stark belastet ist, zeigt die neue Geometrie geringere Reibungsverluste als ein herkömmliches Kegelrollenlager. Um diese Prämisse zu bestätigen und das Modell zu validieren, wurde ein Prototyp der neuen optimierten Geometrie hergestellt und dieser, zusammen mit einem Kegelrollenlager mit den gleichen Hauptabmessungen, experimentell getestet. Die Untersuchungen wurden an einem Reibmomentprüfstand durchgeführt, mit dem die an einem Lager auftretenden Belastungen und Fehlausrichtungen realistisch reproduziert werden können.

Die Ergebnisse dieser Untersuchungen sowie ihr Vergleich mit den simulativen Ergebnissen der Mehrkörpersimulationsmodelle werden hier gezeigt und diskutiert. Es ist festzustellen, dass das neue Modell des Prototyps nicht nur validiert werden kann, sondern auch unter einigen Betriebspunkten mit stark belasteten Lagern weniger Reibungsverluste als ein vergleichbares Kegelrollenlager aufweist.

Availability of data and material Not applicable

Code availability Not applicable

Margarita Mármol Fernández

margarita.marmol@mv.uni-kl.de
1 Institute of machine elements, gears and transmissions, Tu Kaiserslautern, Kaiserslautern, Germany 


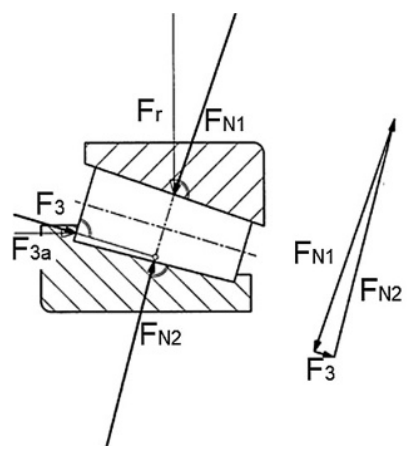

Fr external radial force

$\mathrm{F}_{\mathrm{N} 1}$ normal force at the outer ring

FN2 normal force at the inner ring

$\mathrm{F}_{3}$ pressing force

$\mathrm{F}_{3 a}$ induced axial force

Fig. 1 Forces on a tapered roller bearing [1]

\section{Introduction}

The losses occurring in rolling bearings due to friction are of major importance and have an influence in the dynamic performance, vibration, noise, and ultimately, lifetime. The focus of this research is towards those cases where tapered roller bearings are used to solve an adjusted bearing arrangement. When a tapered roller bearing is loaded, the cone-shaped rolling element geometry leads to a resultant normal force acting in the flange of the inner ring (see Fig. 1), which in turn leads to high friction losses appearing in the guide flange. The ratio of this friction to the total friction losses of the roller bearing depends on many factors e.g. rotational speed, load, lubrication; all affecting the lubrication condition at the flange. In cases of mixed friction, the friction losses at the flange are at its maximum and dominating over the others $[1,2]$.

In order to avoid the flange and its consequence friction, a tandem angular contact ball bearing, has been found to be a proper substitute for cases with low to medium loads, as it is the case of axle gears of passenger cars. The re- duction of the friction torque when exchanging the regular tapered roller bearings with tandem ball bearings is shown in Fig. 2. Because of its point contact, this type of bearing shows less carrying capacity than a tapered roller bearing. Taking the main dimensions of $80 \mathrm{~mm}$ for the outside diameter and $40 \mathrm{~mm}$ for the inside diameter, the tandem angular contact ball bearing has basic load ratings of $\mathrm{C}_{\mathrm{r}}=71.7 \mathrm{kN}$ and $\mathrm{C}_{0 \mathrm{r}}=50.3 \mathrm{kN}, 46 \%$ less in case of static loads and $29 \%$ less for dynamic loads compared to the ones of a tapered roller bearing $\left(\mathrm{C}_{\mathrm{r}}=98 \mathrm{kN}\right.$ and $\left.\mathrm{C}_{0}=93 \mathrm{kN}\right)$.

For cases with highly loaded rolling bearings in both axial and radial direction, a suitable alternative has not been found so far. With the goal of meeting this need, several geometries of roller bearing, as well as the dependencies between these geometries and the frictional torque have been studied. Combining geometrical characteristics of already existing roller bearings, as well as patents on this field [3-7], it is possible to obtain a new geometry which combines the advantages that are looked for: high carrying capacity in both axial and radial directions (tapered roller bearings), flange contact missing, high tolerance against roller tilting and skewing (barrel roller bearings). Based on this premise, a new geometry has been developed and optimized.

The starting point for the new design has been a tapered barrel roller bearing, a new type of rolling bearing described in the Patent of Jacob in 2008 [3]. The reduction of the friction losses when using a tapered barrel roller bearing in comparison with a tapered roller bearing has already been studied at the MEGT chair in Kaiserslautern; its results will be shown later on. The optimization of the new geometry has been done within a Multi-Body Simulation (MBS) Model. The process to build this model, together with its validation comparing simulative and experimen-
Fig. 2 Resulting torque for tapered roller bearing compared to tandem angular contact bearing [2]

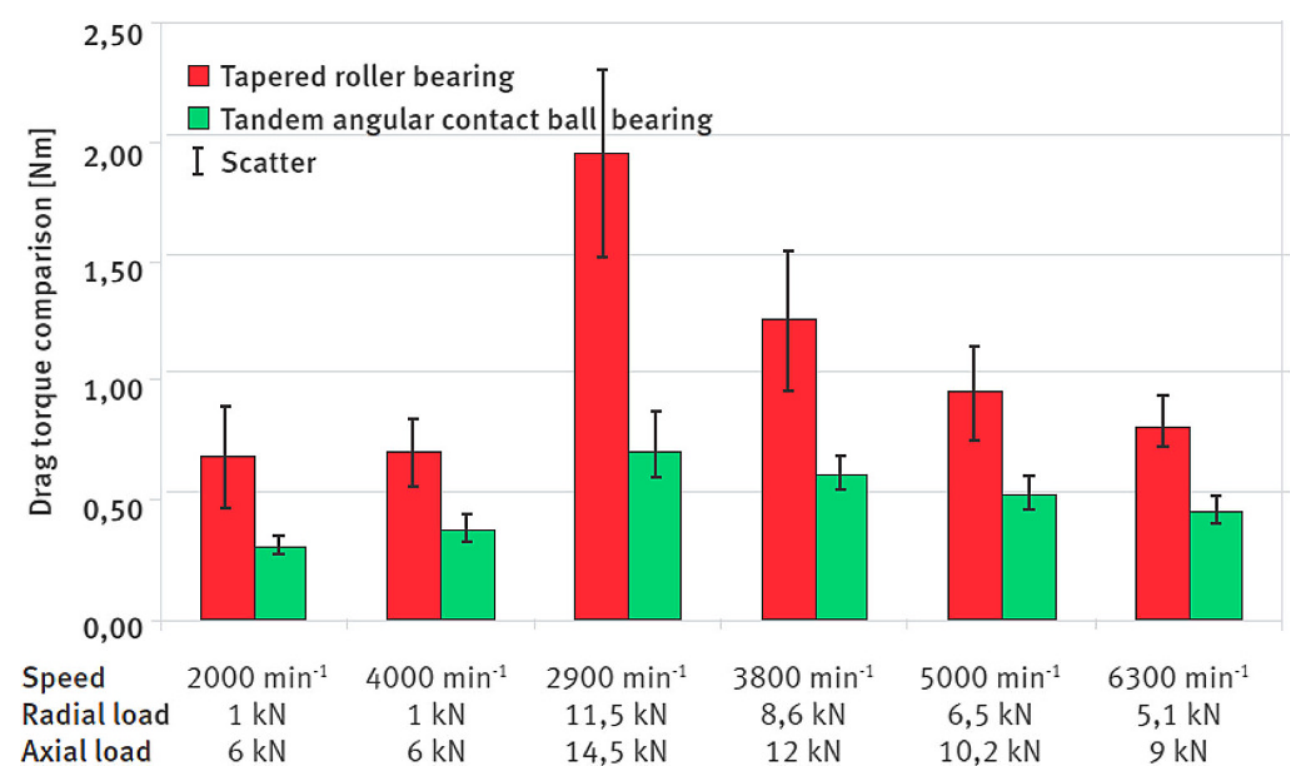


Fig. 3 Comparison of the geometrical variables defining a tapered roller bearing and the new rolling bearing under study

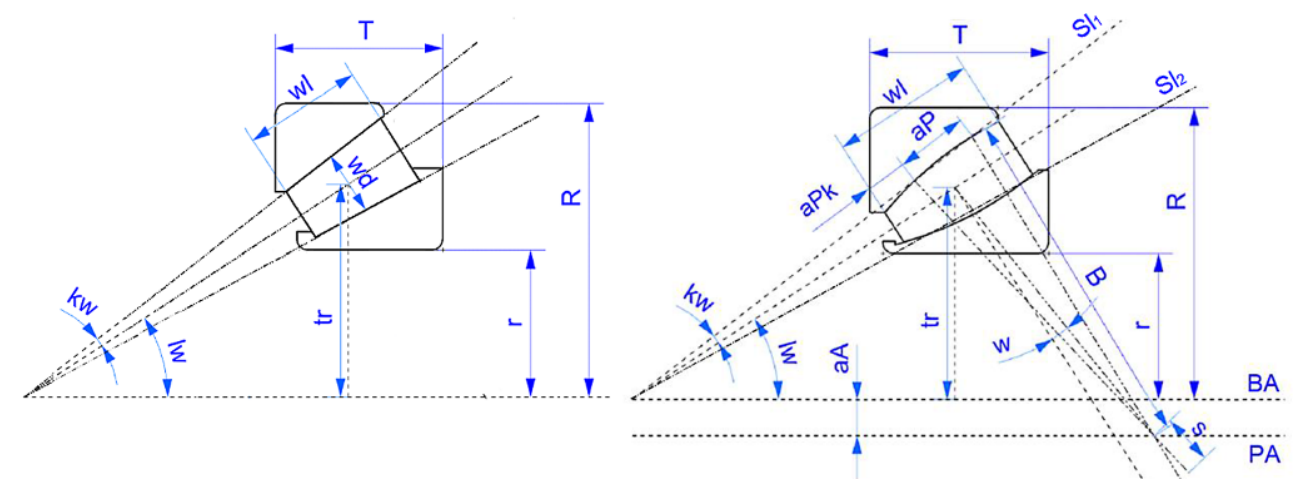

tally obtained results, as well as the discussion of some of these results will be further presented below.

\section{Simulation model}

\subsection{State of the art}

The calculation routines for tapered roller bearings already developed at the MEGT chair were the starting point of the work. These routines, where advanced slice models are used for the calculation of the highly loaded EHL contacts, are contained in a MBS model. This existing model, as well as its procedure of computation and evaluation, has been validated and presented in several studies [8-13]. In order to create the routines for the new geometry, the main focus is to change the geometrical definition of it as well as the calculation routines obtaining the penetration (negative distance between the two contacting surfaces or the theoretical penetration depth of the undeformed surfaces), the location of the contact points and the contact directions. Once these changes have been done, the other existing routines to obtain the forces and torques considering damping and lubrication can be directly used.

\subsection{Geometrical definition}

Based on the patent of Jacob for a tapered barrel roller bearing as well as other existing universal models [4-7], the new geometry was defined within 11 variables of lengths and angles, in such a way, that there is no need of a flange. This geometrical definition, together with the geometry of a tapered roller bearing is shown in Fig. 3, The MBS model created defines the geometry of rolling elements, races and cage depending on the values given to these variables. In order to obtain a geometry with lower friction losses than tapered roller bearings while maintaining high radial load carrying capacity when subject to high loads, the dependence of these variables on the resultant frictional torque and maximum pressure was the main focus of the simula- tion. Some geometrical characteristics that were taken into consideration in order to obtain an optimal geometry are explained below.

As it is known from toroidal roller bearings in comparison with for e.g., spherical roller bearings, when the design is such that the profile curve radii $(B)$ of the raceways and the rollers are considerably bigger, the rollers can be made longer (bigger $w l$ ) than what is possible in such spherical bearings which enhances the radial load carrying capacity. In terms of our geometry this means high value of $a A$ compared to when $a A$ is equal 0 (as it is the case of the patent of Jacob), and a profile curve axle ( $P A)$ not laying at the bearing axle $(B A)$ anymore. Ensuring that both of the surface lines $\left(S l_{1}\right.$ and $\left.S l_{2}\right)$ of the roller cut at the bearing axle, we will obtain an even distribution of pressure within the contact area, which turns into symmetrically loaded rollers and no slippage. In these terms, the tapered angle $(k w)$ is a direct function of the contact angle $(l w)$. Since the geometry looked for is one to be operating under high axial forces, the contact angle will be chosen in accordance. Being the osculation defined as the ratio between the radius of curvature of the roller and the one of the raceways; a smaller osculation (bigger $s$ ) turns into a more concentrated area of contact at its contact points. This, together with the distance between contact points $(a P)$ and the location of these
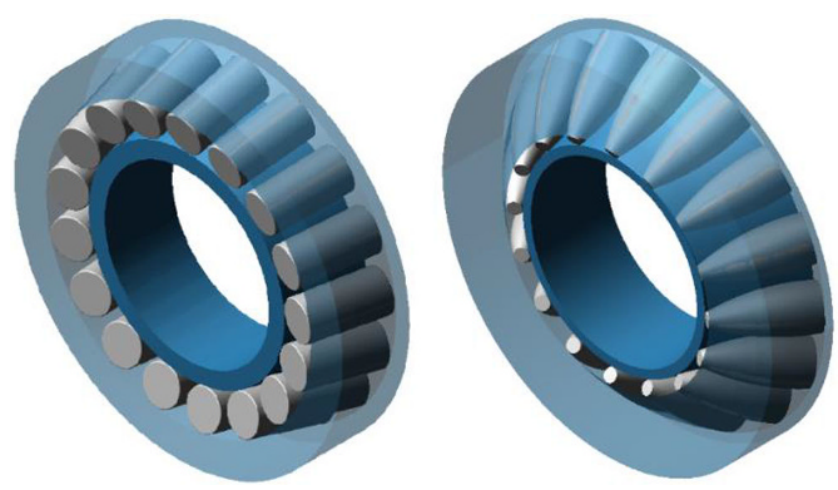

Fig. 4 Representation of two simulations models. On the left a 32208 tapered roller bearing and on the right an example of the geometry under study 
points (defined by $w$ or $a P k$ ), have a major influence on the contact pressure and the possible skewing of the rollers.

In order to optimize the geometry, a starting simulation matrix with several geometries and load conditions was defined. The results of these geometries in terms of pressure and frictional torque and its dependencies with the changes on the parameters was studied. According to the observed influence of the parameters on the results, a new matrix with new changes in the parameters defining the geometries was generated, simulated and again studied. This iterative process was repeated, till the optimized geometry was found [19, 20].

Fig. 4 shows a representation example of both models. The first one has the dimensions of a 32208 tapered roller bearing and, therefore, the second one shows a new geometry with the approximate same main dimensions $\mathrm{T}, \mathrm{r}, \mathrm{R}, \mathrm{tr}$ from Fig. 2.

\section{Experimental tests}

\subsection{Previously obtained results and first validation}

As mentioned before, a tapered barrel roller bearing has already been studied and compared with a tapered roller bearing at the MEGT chair in Kaiserslautern. Within this work, a prototype of a tapered barrel roller bearing, without an optimized geometry or surface finish $(\mathrm{Ra}=0.15 \mu \mathrm{m})$, has already shown a frictional torque comparable to the one of a tapered roller bearing of the same main dimensions (32314A), having an optimal flange geometry and high quality surface finish $(\mathrm{Ra}=0.03 \mu \mathrm{m})$. In this study, both roller bearings (of $70 \mathrm{~mm}$ shaft diameter) where submitted to an axial load of $20 \mathrm{kN}$ and variable radial load from -20 to $20 \mathrm{kN}$.

The first validation of the MBS model, before a prototype of the optimized geometry could be manufactured, was taken place comparing its simulated values to the experimental values that were obtained in this study. As shown in Fig. 5 we can see that the frictional torque obtained in the simulation when submitted to an axial load of $20 \mathrm{kN}$

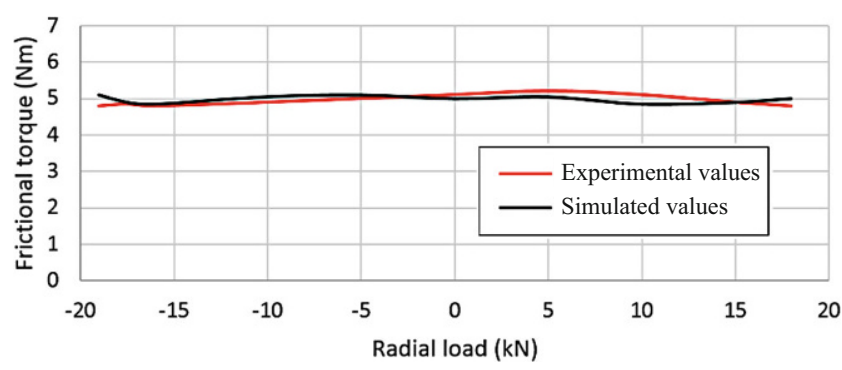

Fig. 5 Comparison of the experimental and simulated results of the frictional torque for a tapered barrel roller bearing with the main dimensions of a 32314

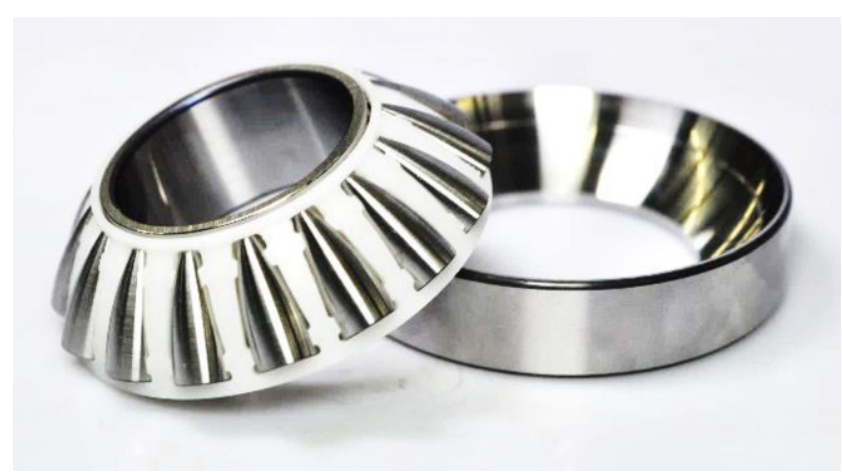

Fig. 6 Prototype of the new geometry with polymer cage

is about $5 \mathrm{Nm}$, where the radial load has a minimal influence on it. This is the same outcome as the one obtained in the original study at the MEGT chair. It is to be mentioned, that this bearing is a much bigger one, than the one that has been studied afterwards. $(d=70 \mathrm{~mm}, D=150 \mathrm{~mm}$; compared to $d=40 \mathrm{~mm}, \mathrm{D}=80 \mathrm{~mm}$ ).

\subsection{Prototype}

In order to be able to compare the new geometry with a tapered roller bearing 32208, two prototypes of the geometry selected as optimal, with main dimensions comparable to a 32208 were produced (Fig. 6). The parameters defining this geometry accordantly to Fig. 2 are shown on Table 1. Other dimensions and its comparison to the one of a 32208 are shown on Table 2 . These prototypes have a cage made of a conventional polymer cage material (Polyamide 66).

\subsection{Test bench and test plan}

With the frictional torque test rig it is possible to realistically reproduce the loads occurring on a bearing in reality, see Fig. 7. The friction torque of a test bearing installed in the test module can be measured as a function of a combined bearing load from axial and radial load and additional bearing misalignment using the rotational movement of the test bearing outer ring. For this purpose, the outer ring of the test bearing is mounted in a hydrostatic bearing, which enables the friction torque of the test bearing to be measured, since the rotational degree of freedom of the hydrostatic bearing is recorded with a bending beam force sensor. The radial load on the test bearing is applied indirectly via the support bearings of the load module with a load screw. The adjustment of the misalignment can be set independently of the bearing load. For this purpose, the tilt module has a linear guide, which in turn is mounted in a rotary guide. For the tilted position the support bearings of the tilt module can be moved in the radial direction. The angular position can be set between 0 and $90^{\circ}$ to the radial load direction, so 
Table 1 Parameters of the prototype according to Fig. 3

\begin{tabular}{|c|c|c|c|}
\hline Description & Variable & Value & Unit \\
\hline Width & $\mathrm{T}$ & 24.75 & $\mathrm{~mm}$ \\
\hline Shaft radius & $\mathrm{r}$ & 20 & $\mathrm{~mm}$ \\
\hline Outer radius & $\mathrm{R}$ & 40 & $\mathrm{~mm}$ \\
\hline Pitch circle radius & $\operatorname{tr}$ & 29 & $\mathrm{~mm}$ \\
\hline Taper angle & kw & 4.5 & $\circ$ \\
\hline Raceway angle & lw & 33 & $\circ$ \\
\hline Angle to the perpendicular to the axis of rotation of the barrels center plane & $\mathrm{w}$ & 10 & $\circ$ \\
\hline Length of the rolling element & wl & 20 & $\mathrm{~mm}$ \\
\hline Distance between the osculation contact points & $\mathrm{aP}$ & 8 & $\mathrm{~mm}$ \\
\hline $\begin{array}{l}\text { Distance between bearing axis and axis for the center of curvature of the rolling element outer } \\
\text { surface }\end{array}$ & $\mathrm{aA}$ & 0.25 & $\mathrm{~mm}$ \\
\hline $\begin{array}{l}\text { Difference between the radius of curvature of the osculation area and of the outer surface of } \\
\text { the rolling element }\end{array}$ & $\mathrm{s}$ & 3 & $\mathrm{~mm}$ \\
\hline
\end{tabular}

Fig. 7 Test bench
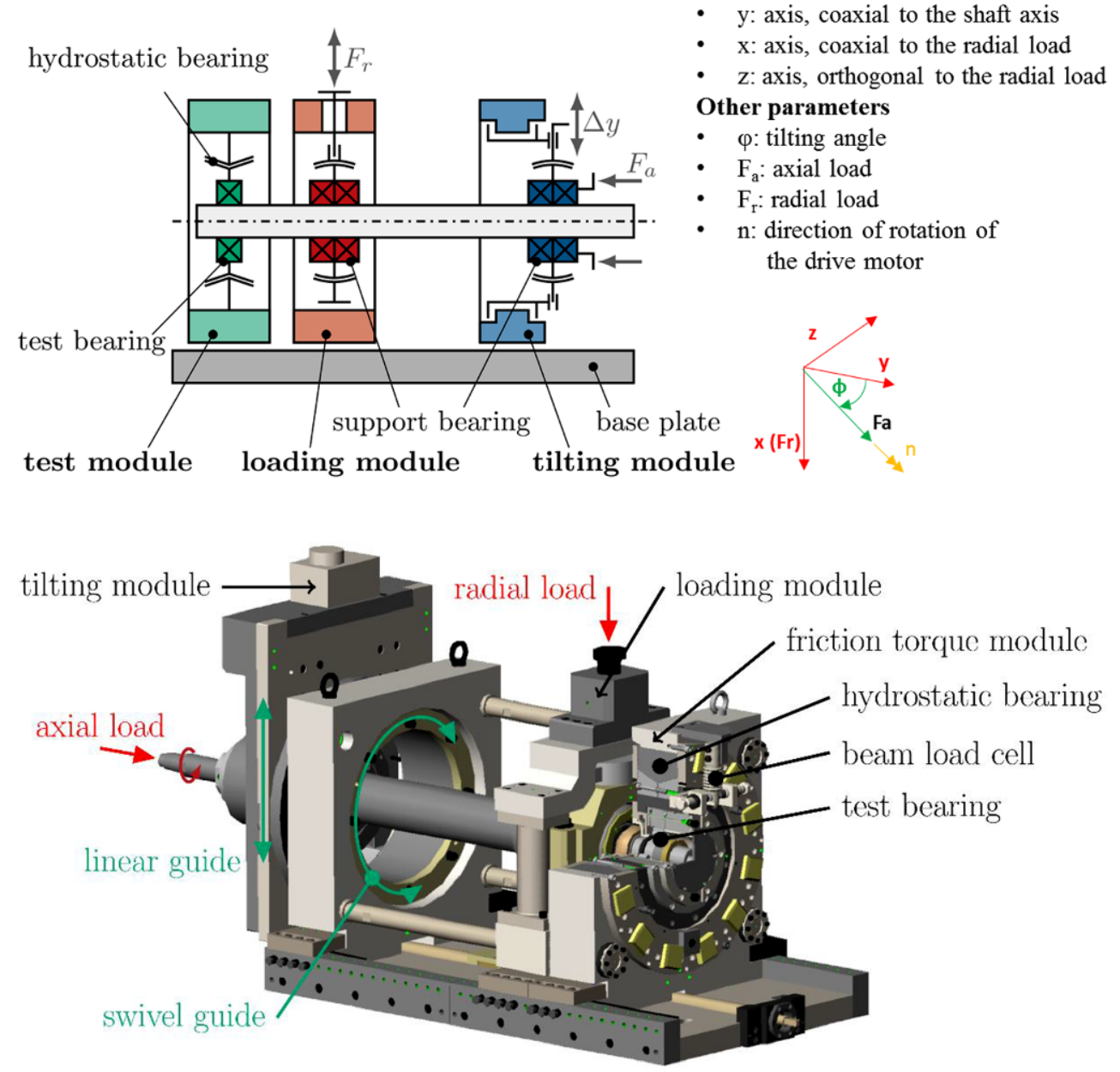

that tilting and skewing or combined inclined positions can be set. In addition, an axial force can also be applied via the support bearing of the tilting module by means of a hydraulic cylinder. The support bearings of the tilt and load module are accommodated in spherical calottes to compensate the tilting position.
The flying test bearing is accessible from one side, so that from this side the cage speed can be recorded with the help of inductive sensors. Depending on the cage geometry, the cage pocket and rolling element passes are recorded and converted to the cage speed. The lubrication is carried out as oil bath lubrication with FVA reference oil No. 3. The 
Table 2 Boundary conditions for the MBS Model

\begin{tabular}{|c|c|c|c|}
\hline Description & Variable & Value (Prototype/32208) & Units \\
\hline Outside diameter & $\mathrm{D}$ & 80 & $\mathrm{~mm}$ \\
\hline Inside diameter & $\mathrm{d}$ & 40 & $\mathrm{~mm}$ \\
\hline Pitch diameter & $\mathrm{d}_{\mathrm{TK}}$ & $58 / 60$ & $\mathrm{~mm}$ \\
\hline Contact angle & $\alpha$ & $33 / 14$ & $\circ$ \\
\hline Rolling elements length & $1_{\mathrm{WK}}$ & $20 / 17.1$ & $\mathrm{~mm}$ \\
\hline Number of rolling elements & nwK & 17 & - \\
\hline Young's modulus & $\mathrm{E}$ & 208,000 & $\mathrm{~N} / \mathrm{mm}^{2}$ \\
\hline Poisson's ratio & $v$ & 0.3 & - \\
\hline Density & $\rho$ & 7850 & $\mathrm{~kg} / \mathrm{m}^{3}$ \\
\hline Parameters for the logarithmic profile according to TEUTSCH [13] & $a_{p}$ & $-/ 0.0005$ & - \\
\hline$\xi_{\mathrm{k}} \quad \mathrm{k}_{\mathrm{p}}$ & $c_{p}$ & $-/ 15.5$ & $\mathrm{~mm}$ \\
\hline$\leftarrow$ & $d_{p}$ & $-/ 0$ & $\mathrm{~mm}$ \\
\hline$\rightarrow$ & $\mathrm{k}_{\mathrm{p}}$ & $-/ 2.0$ & $\mathrm{~mm}$ \\
\hline
\end{tabular}

$\mathrm{D}$

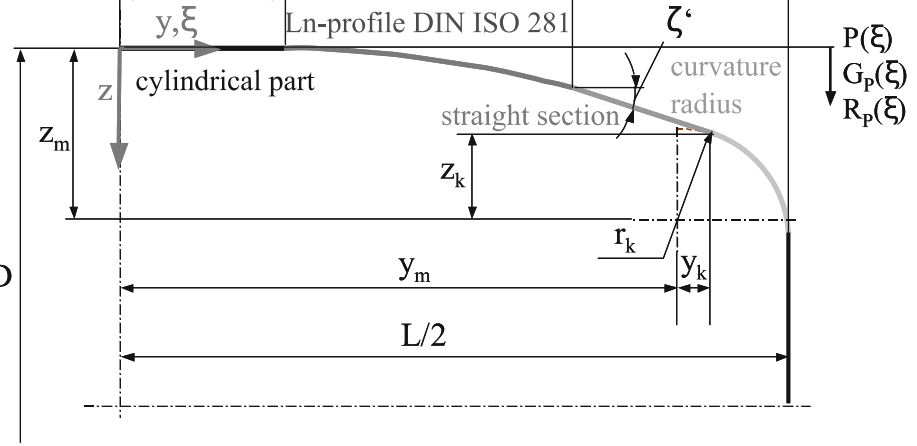

$-/ 2.0$

ym,RE-end

$\mathrm{y}_{\mathrm{k}, \mathrm{RE} \text {-end }}$

$\mathrm{Z}_{\mathrm{m}, \mathrm{RE}-\mathrm{end}}$

Zk,RE-end

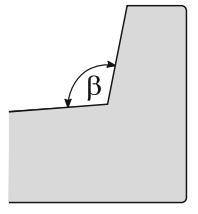

(Conical board)

(Roller end profiled with edge radius)

Edge radius

Roughness (RW= Raceway; $\mathrm{RE}=$ Rolling elements)

Combined roughness standard deviation

Raceway contact mixed friction parameters according to ZHOU and HOEPRICH [14]

Roller end-rib contact mixed friction parameters according to ZHOU and HOEPRICH [14]

Lubricant

Lubricant temperature

Lubricant viscosity

Lubricant density

\begin{tabular}{lll}
$\mathrm{r}_{\mathrm{k}}$ & $-/ 0.8$ & $\mathrm{~mm}$ \\
$\mathrm{~s}_{\mathrm{q}, \mathrm{RW}}$ & $0.14 / 0.22$ & $\mu \mathrm{m}$ \\
$\mathrm{s}_{\mathrm{q}, \mathrm{RE}}$ & $0.17 / 0.24$ & \\
$\mathrm{~s}_{\mathrm{q}, \mathrm{Rib}}$ & $-/ 0.26$ & \\
$\mathrm{~s}_{\mathrm{q}, \mathrm{RE}-\text {-end }}$ & $-/ 0.28$ & \\
$\sigma_{\mathrm{LB}}$ & $0.22 / 0.33$ & $\mu \mathrm{m}$ \\
$\sigma_{\text {Rib-RE-end }}$ & $-/ 0.38$ & \\
$\mathrm{~B}_{\mathrm{ZH}}$ & $1.7 / 2.27$ & - \\
$\mathrm{C}_{\mathrm{ZH}}$ & $0.8 / 1.05$ & \\
& & \\
$\mathrm{~B}_{\mathrm{ZH}}$ & $-/ 1.78$ & - \\
$\mathrm{C}_{\mathrm{ZH}}$ & $-/ 1.01$ & \\
- & FVA-Reference Oil Nr. 3 & - \\
& (unadditivated mineral oil) & \\
$\mathrm{T}_{\text {Öl }}$ & $50-60$ & ${ }^{\circ} \mathrm{C}$ \\
$v_{\text {Öl }}$ & $57.01-36.88$ & $\mathrm{~mm}{ }^{2} / \mathrm{s}$ \\
$\rho_{O ̈ 1}$ & $0.86-0.85$ & $\mathrm{~g} / \mathrm{ml}$ \\
\hline
\end{tabular}


Table 3 Boundary conditions for verification of the simulation model

\begin{tabular}{ll} 
Shaft diameter & $40 \mathrm{~mm}$ \\
Radial load & 0 to $8 \mathrm{kN}$ \\
Axial load & 0 to $5 \mathrm{kN}$ \\
Shaft speed & $2000 / 4000 \mathrm{rpm}$ \\
Tilting prototype & 0 to $0.5^{\circ}$ \\
Tilting 32208 & 0 to $2.5^{\prime}$ \\
\hline
\end{tabular}

test chamber is filled with lubricant up to half the height of the lowest rolling element at standstill.

The frictional torque is used as an integral variable to validate the dynamics of the MBS model. The determination of the surface data required for the simulation was carried out using measurements on a 3D confocal microscope from NanoFocus. The combined standard deviation of the roughness in the contact rolling element-raceway, which is used in the simulation, is $0.22 \mu \mathrm{m}$ for the prototype and
$0.33 \mu \mathrm{m}$ for the tapered roller bearing. The parameters for the investigation are summarized in Table 3.

\section{Model validation. Comparison of the simulation and the experimental results}

The new prototype, as well as a comparable tapered roller bearing 32208 have been experimentally tested. The results of these experiments, compared with its simulation, are shown in Figs. 8, 9 and 10 when running at a speed of $2000 \mathrm{rpm}$. Due to limited temperature control possibilities on the test rig, the temperature at $2000 \mathrm{rpm}$ is in the range of $50-60{ }^{\circ} \mathrm{C}$.

Fig. 8 shows the resulting frictional torque for different radial loads at a constant axial load of $3 \mathrm{kN}$ and $4.5 \mathrm{kN}$, as well as for different axial load when the radial load is $0 \mathrm{kN}$, again at $2000 \mathrm{rpm}$. The illustration shows that the model used, together with the integrated calculation routines is
Fig. 8 Simulation and experimental results of frictional torque for different load conditions for the Prototype

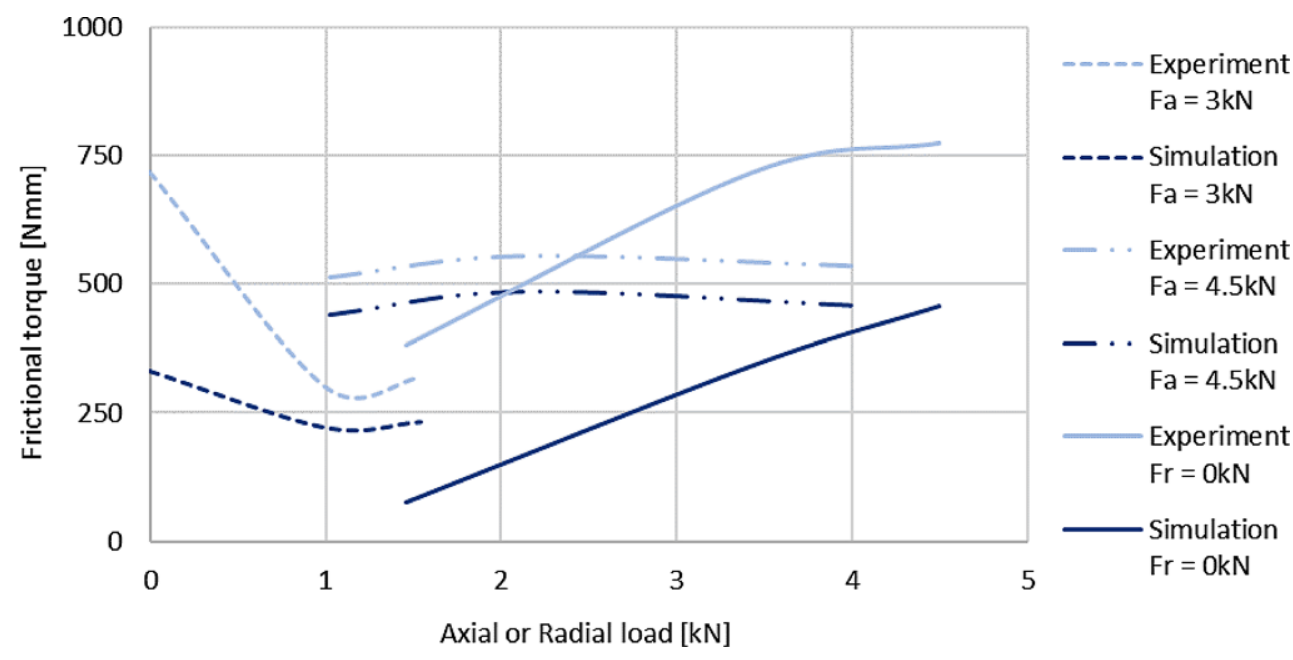

Fig. 9 Accuracy of the simulation model both for the prototype and the tapered roller bearing for different dynamic bearing load

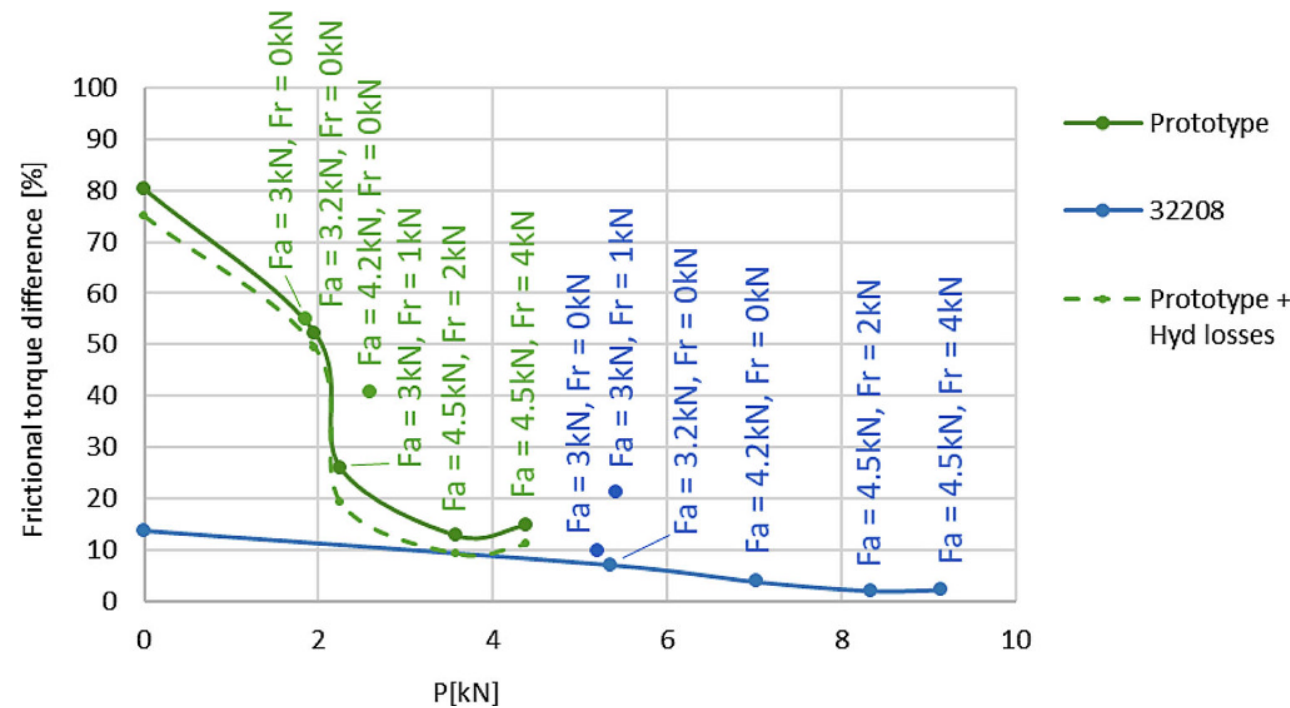


suitable, since the influence of the load can be correctly predicted. At pure axial load we can see that the curves show an almost linear increase in the frictional torque with increasing axial load. Given the comparatively lower purely axial load present, it can be assumed that the drilling friction taking place at the prototype similar to the edge friction of the tapered roller bearing outweigh the other types of friction, being both directly proportional to the load.

It should also be pointed that the slight influence of the radial load on the frictional torque of the prototype, which can be mostly observed for the line of higher axial load, is $4.5 \mathrm{kN}$. This is due to a reduction in the circumferential load zone when introducing a radial load component compared with pure axial loading, which turns into fewer rolling elements getting more loaded. But due to the approximately degressive increase in the frictional torque, the total frictional torque remains at a comparable level or is slightly reduced.

Fig. 9 represents the accuracy of the models in percentage by comparing the experimental and simulation results for both the prototype (green line) and the tapered roller bearing (blue line), compared to the dynamic bearing load, P. The calculation of $\mathrm{P}$ has been done according to ISO 281, using the following equations:

$P_{r}=X \times F_{r}+Y \times F_{a}$

$X=0.4 ; Y=0.4 \times \cot \alpha$

It can be mentioned, that since the prototype has much bigger contact angles than the 32208 bearing ( 33 to $14^{\circ}$ ), the influence of the axial load in the dynamic bearing load is much smaller for the prototype. In the case of the load conditions studied in the experiments, this turns into much smaller dynamic bearing loads for the prototype. Since the dynamic bearing load depends on both the axial and the radial load, we obtain similar values for different load conditions. In this case, only one point has been considered in order to represent the tendency, while the other points are individually represented.

For all the load scenarios, it can be seen that the simulation underestimates the measurement for both bearings, with a bigger difference for the prototype than for the tapered roller bearing. It could be assumed, that the model is validated when the difference of the simulations with the experiments is under $20 \%$, with regard to further uncertainties always to be considered in the experiment. For the tapered roller bearing model, which has been used for many years and has been deeply studied [12], we obtain a precision of less than $10 \%$ for most of the cases. This percentage decreases with increasing load, since we have a more defined contact situation as well as less sliding in the bearing. This behavior is even more noticed for the prototype, which model has been designed for high load conditions. With this finding it would be recommended to set the minimum load for the prototype to at least $2 \mathrm{kN}$. In order to better map the influence of slip in the simulation for the prototype, the results of the recently completed project FVA $830 \mathrm{I}-$ Minimum load of rolling bearings will be included in future optimization steps [15]. For the experimental validation, it will then be necessary to measure the cage speed and the rolling element speed for investigating the rolling bearing kinematics. Deviations can also be attributed, for example, to the lubricant temperature, which cannot be precisely measured. In addition, there is still potential to optimize the model with regard to the consideration of the contact stiffness in order to model the real surface roughness in the simulation. The measured surfaces of the contact partners can be used in a finite element simulation to map the non-linear material behavior. The results can then be used as input variables for the multi-body simulation.

Since the geometry of the prototype has not been studied before, it is impossible to know for certain, what is the weight of the hydraulic losses in the total frictional torque, in order to add those into the model. For the tapered roller
Fig. 10 Comparison of the frictional torques from simulation and measurement with variation of the tilt angle

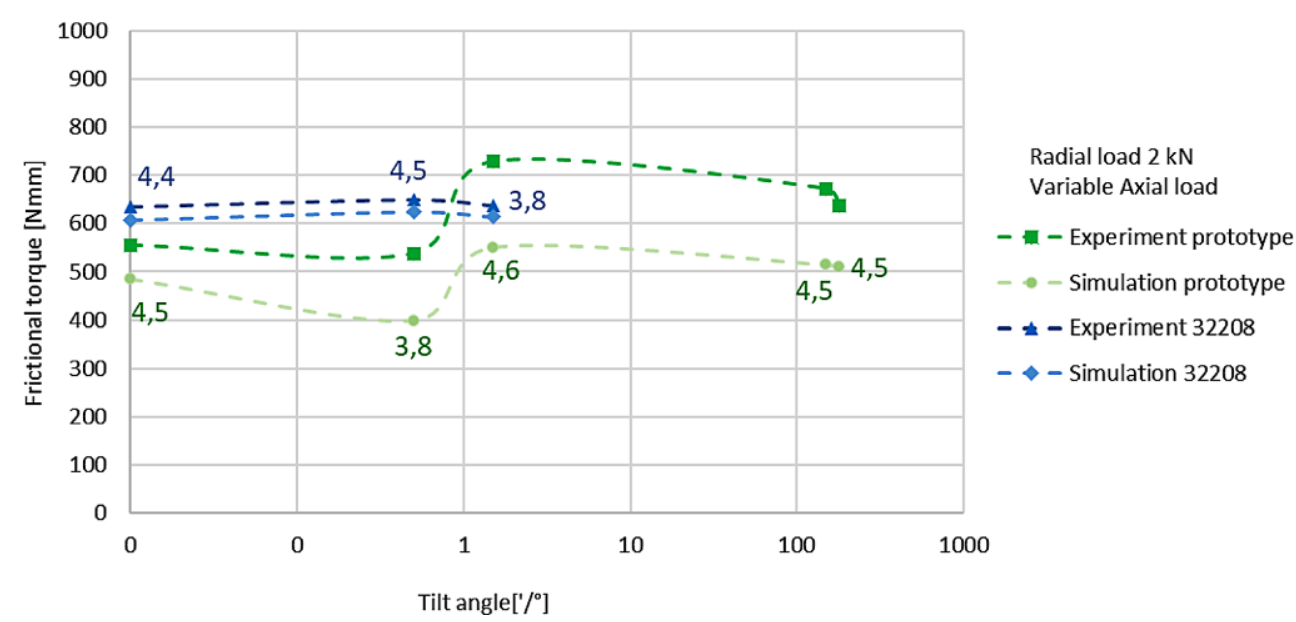


Fig. 11 Ratio dynamic bearing load (P) to dynamic load rating $(\mathrm{C})$ of both tapered roller bearing and prototype for each load condition

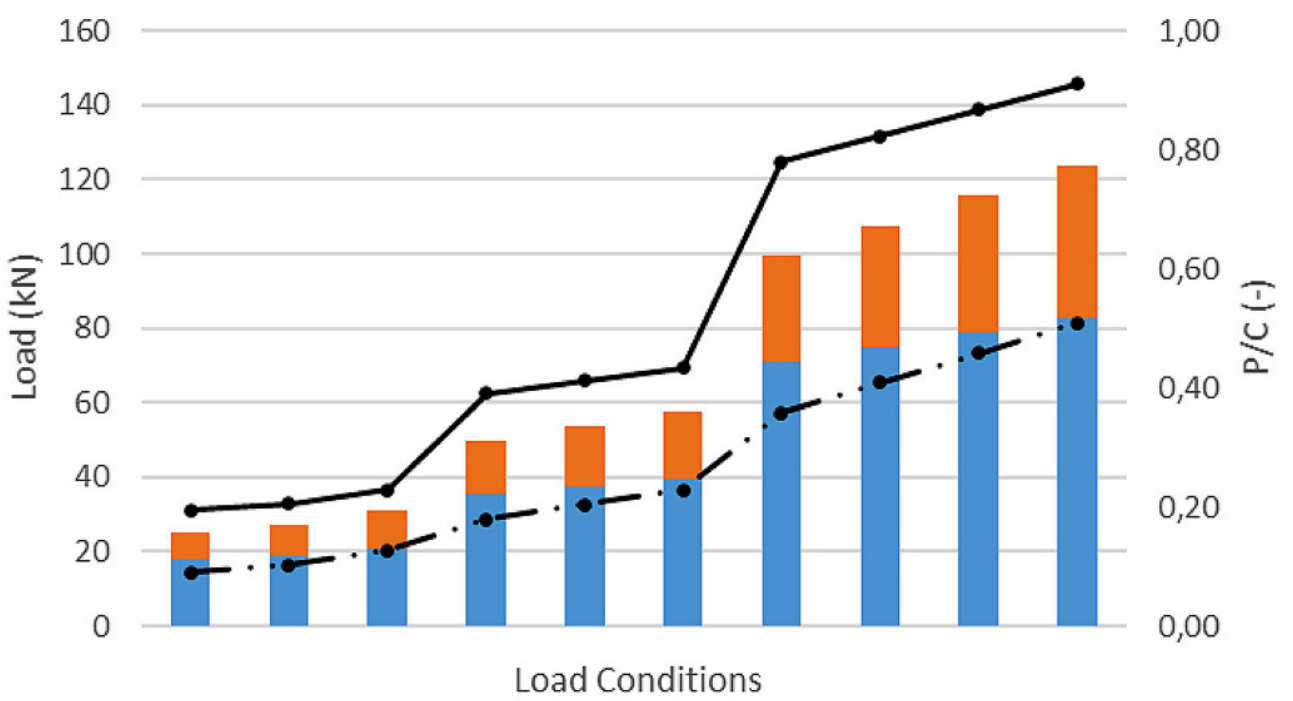

Axial Force Radial Force $\longrightarrow$ P/C (32208) $\mathrm{P} / \mathrm{C}$ (Prototype) bearing model, these are determined within the calculation routines according to the technical-mathematical approach to calculate the drag and churning losses developed for tapered roller bearings [16], which has been validated for different types of bearings [17]. In [18], the transferability to rolling bearings with cylindrical rolling elements in a horizontal arrangement has already been shown. Based on this, the present case results exclusively in churning losses that apply to the complete set of rolling elements. Adding this information to the simulation results, we obtain a much more accurate model (represented in Fig. 10 by a green broken line) for the prototype. The validation of the technicalmathematical approach for the geometry of the prototype is yet to be studied, and will be under consideration for future studies at the MEGT chair.

Fig. 10 shows in logarithmic scale the frictional torques for the two test bearings and the simulation results at different tilt angles. The tilting takes place in the opposite direction to the direction in which the radial load is applied. With a constant radial load of $2 \mathrm{kN}$, the axial load varies from 3.8 to $4.6 \mathrm{kN}$ between points, with a constant value for the simulation and the experiment. The value of the axial force for each point can be read in the graphic. According to the bearing manufacturer, the maximum tilt of the tapered roller bearing must not exceed $4^{\prime}$, which is why the last two test points $0.25^{\circ}$ and $0.5^{\circ}$ were only measured for the prototype. When looking at the results, the frictional torques for the tapered roller bearing are above those of the prototype in two of the three comparable measuring points. In general, it should be noted that an increase in the tilt has no noticeable influence on the frictional torque, taking into consideration differences in the axial load already mentioned. In the simulation, the curves coincide with the experimentally determined values in terms of both amount and course, with an accuracy of $96 \%$ for the tapered roller bearing and between 76 and $87 \%$ for the prototype.

\section{Other simulation results}

Once the simulation model has been validated, other simulations can be run, as well as other interesting results can be obtained from it. The test bench has limited load conditions for this size of bearings up to $5 \mathrm{kN}$ in axial direction and $8 \mathrm{kN}$ radial. However, the prototype has been designed to cover the need of a bearing with lower frictional torque for cases with high load conditions. According to ISO 281, Eq. 13, and considering a $b_{m}$ value of 1.125 (resulting from the combination of the geometries of tapered roller bearings and spherical roller bearings), the prototype would have a dynamic load rating of $73 \mathrm{kN}$, compared to the $91 \mathrm{kN}$ of the 32208 bearing. In this terms, new simulations have been run with higher loads up to $40 \mathrm{kN}$ in both axial and radial direction. Considering the difference in the contact angle mentioned before, this load condition turns into a dynamic bearing load $\mathrm{P}$ of $82.9 \mathrm{kN}$ and $40.6 \mathrm{kN}$ for the tapered roller bearing and prototype respectively. The resultant ratio dynamic bearing load to dynamic load rating for both bearings and each load condition under study is shown in Fig. 11.

Besides the results of frictional torque, the maximum pressure in between raceways and rolling elements has also been studied. This pressure is directly related to the lifetime of the bearing, another critical parameter, together with the maximum torque, when choosing a bearing. In general terms, the smaller the contact area at the roller is, the bigger the maximum pressure, and therefore the smaller the frictional torque. A comparison of these results for both types of bearings when running under higher load conditions is 
Fig. 12 Comparison of the raceway pressure and frictional torques for the 32208 and the prototype with variation of the radial force and constant axial forces
Fig. 13 Results of the subtraction of the frictional torque for the prototype from the 32208 bearing (being positive results those where the prototype shows lower frictional torque than the 32208) compared to the ratio of axial force to radial force for the experiments, the corresponding simulation and the simulations shown in Fig. 12
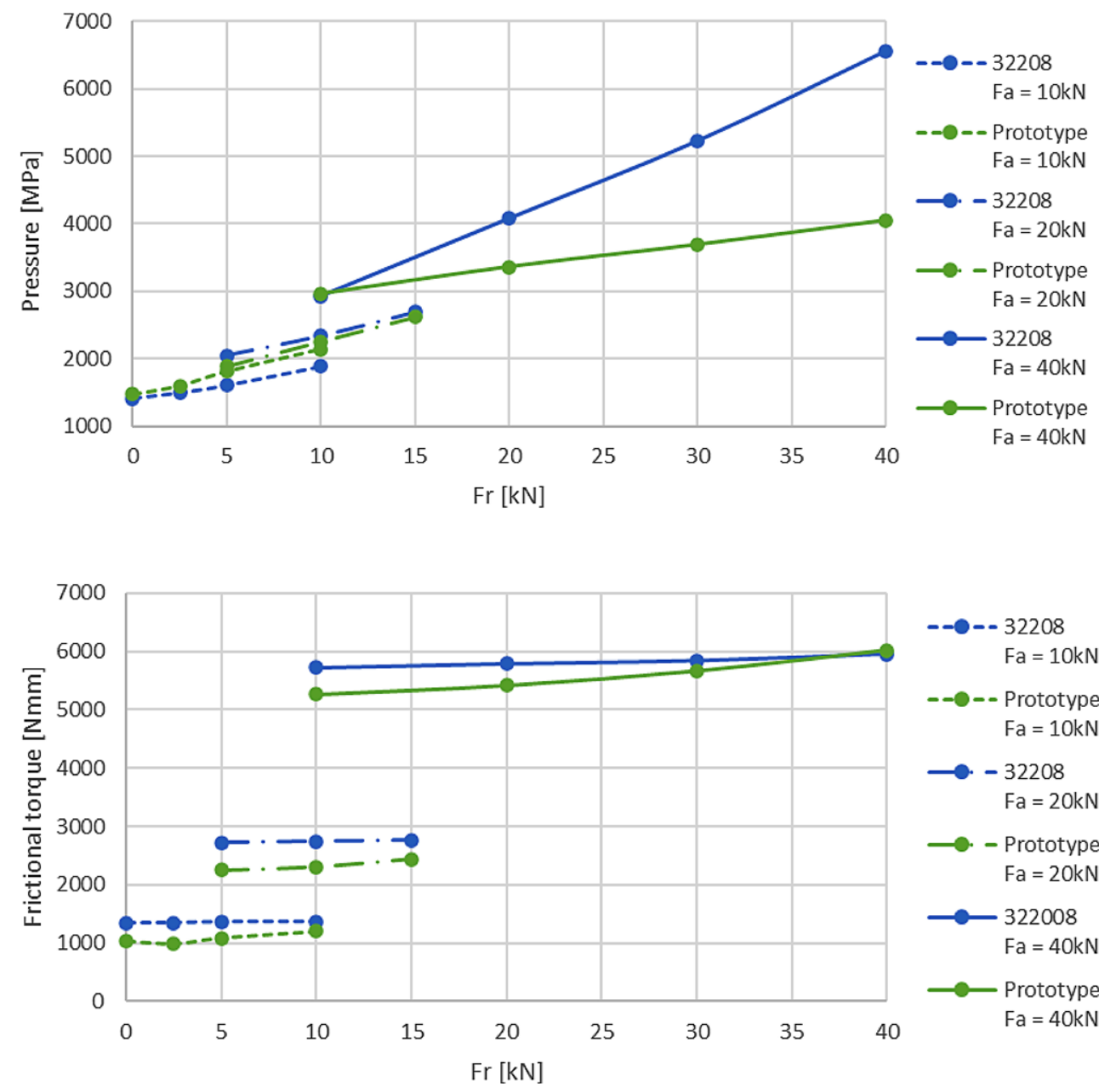

- - - -32208

$\mathrm{Fa}=10 \mathrm{kN}$

- - - - Prototype

$\mathrm{Fa}=10 \mathrm{kN}$

$-32208$

$\mathrm{Fa}=20 \mathrm{kN}$

- Prototype

$\mathrm{Fa}=20 \mathrm{kN}$

$-322008$

$\mathrm{Fa}=40 \mathrm{kN}$

- Prototype

$\mathrm{Fa}=40 \mathrm{kN}$

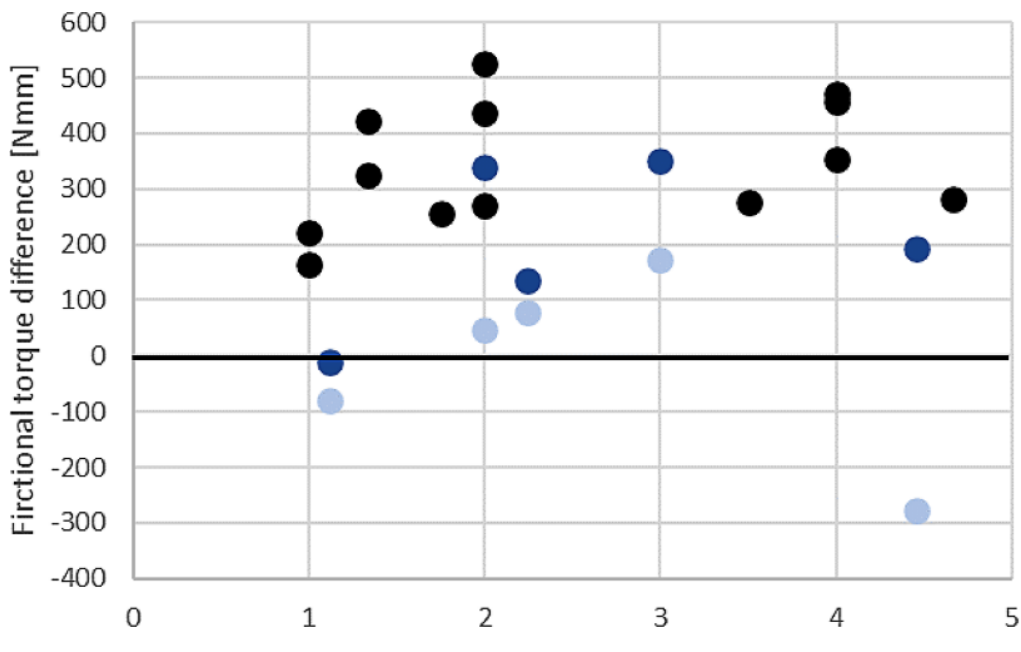

Experiment

Simulation

New simulation higher loads shown in Fig. 12. It can be observed that for all the cases the frictional torque shown by the prototype is smaller than the one by the tapered roller bearing, by factors up to $22 \%$. On the other hand, the prototype shows higher pressure for the case of $10 \mathrm{kN}$ axial force, and smaller for the cases of $20 \mathrm{kN}$ and $40 \mathrm{kN}$ axial force. The high pressure values observed for the tapered roller bearings, appear due to the high value of $\mathrm{P} / \mathrm{C}$ up to 0.91 , while for the prototype is only up to 0.51 because of the differences in the contact angle. The main goal when searching for the new geometry was to 
optimize the frictional torque, and even though it is known that a higher pressure will turn into a shorter lifetime, values of up to $15 \%$ higher, as it is the case for $10 \mathrm{kN}$ axial load, were considered as acceptable.

Fig. 13 shows the differences on the frictional torque between the prototype and the tapered roller bearing compared to the ratio of axial force to radial force. Points over the $\mathrm{x}$-axis represent the scenarios where the prototype has lower frictional torque than the 32208 bearing. The different colors represent the results of the experiments (light blue), the corresponding simulation (dark blue) and the new simulations for higher loads (black). When all results are considered, it can be seen that the prototype has for most of the cases lower frictional torque than the tapered roller bearing of type 32208. It was as well observed, that, compared with tapered roller bearing 32208, the prototype requires a higher axial preload in order to run under optimal conditions and minimum frictional torque, but at the same time can support higher loads in both radial and axial directions.

It should be noted that a direct comparison, for example due to the different contact angles (prototype: $33^{\circ} ; 32208$ : approx. $14^{\circ}$ ) is only of limited significance. This is presumably the reason why, when the ratio between axial and radial load increases, the difference between the prototype and the tapered roller bearing increases for both simulation and experiment. It can be as well observed, that the results obtained from the experiments are more conservative than the ones expected according to the model. Nevertheless, the experiments also show lower friction torque for the prototype for three load conditions. As expected, when the load increases the tapered roller bearing generates more friction than the prototype, also because of the rib contact friction. The reason why for one particular case $\left(\mathrm{F}_{\mathrm{a}} / \mathrm{F}_{\mathrm{r}}=4.5\right.$ with $F_{a}=4.5 \mathrm{kN}$ and $F_{r}=1 \mathrm{kN}$ ), even though the ratio of axial to radial force is high, the tapered roller bearing behaving better than the prototype is a measurement error, due to a mechanical malfunction of the beam load cell.

The results of the simulations for different angular velocities are shown in Fig. 14 for $2000 \mathrm{rpm}$ and $4000 \mathrm{rpm}$. It can be mentioned, that the angular velocity has minimal influence in the resulted frictional torque for both bearings, being this difference slightly bigger for the prototype. We observe lower frictional torque for the prototype compared to the tapered roller bearing for the both angular velocities under study. This difference is, however, reduced when the angular velocity increases. Once the model is validated, further simulations will be conducted in order to determined, whether the reduce of the frictional torque is still to be seen for higher angular velocities. In these terms it is also expected to determine the reference speed for the prototype.

Following on from this project, it is planned to modify the simulation model with regard to the geometry in the direction of radial bearings with a smaller contact angle. It is also planned to produce prototype bearings from this geometry in order to determine the frictional torque experimentally. In the meantime, a new test bench is being built at the MEGT chair, which will be able to run under much higher loads, up to $160 \mathrm{kN}$ radial and $75 \mathrm{kN}$ axial. This will allow us to experimentally test the prototype of the new geometry under much higher loads than was the case for the first geometry.

\section{Summary}

For applications such as axle drives in heavy-duty vehicles, there are currently no solutions for minimizing friction at the bearing points using conventional bearing designs. This
Fig. 14 Comparison of the frictional torques for the prototype and the 32208 when running under different angular speeds of 2000 and $4000 \mathrm{rpm}$ and pure axial load condition

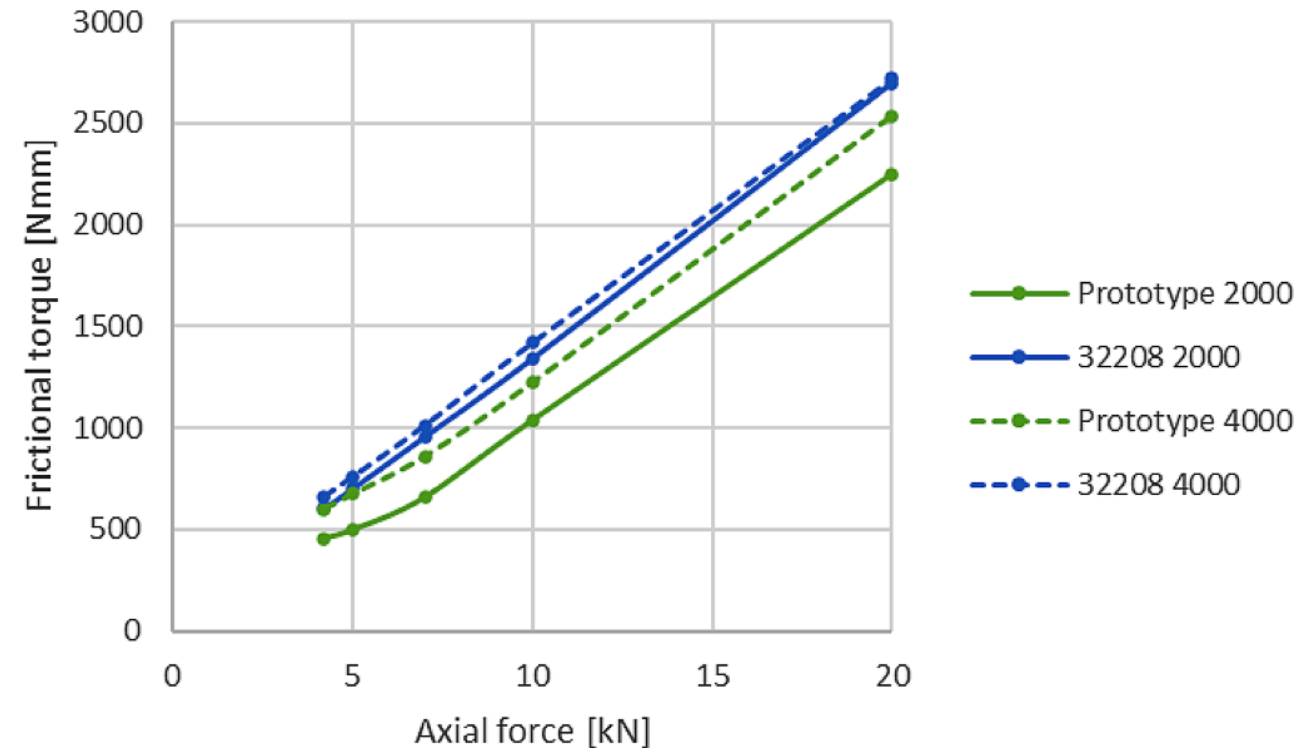


is where the project started, in order to develop a new type of bearing based on the patented design of the tapered barrel roller bearing and thus to achieve optimization with regard to friction losses in highly loaded bearing types.

The constructive bearing design was based on Jacob's patent and other universal models with the result that the design parameter set for friction loss minimization is defined by 11 length and angle variables. From this, a fully parametric 3D model of a tapered barrel roller bearing has been developed in the commercial multi-body simulation environment MSC.ADAMS.

In the first validation step, the developed model was compared with the existing experimental results of a tapered roller bearing 32314A. The influence of the variables from the set of design parameters on the frictional torque and on the pressure in the rolling element raceway contact was then investigated in a parameter study. The objective was to achieve a minimum frictional torque with comparable contact pressure values to tapered roller bearing 32208 , which served as the comparison bearing for the experimental validation. As a result, the operating ranges in which the bearings can be operated were determined. Compared with tapered roller bearing 32208 , the optimized geometry requires a higher axial preload, but at the same time can support higher loads in the radial direction. The optimized geometry was then designed, the associated drawings derived and the prototypes manufactured.

To validate the simulation model, prototype bearings and tapered roller bearings were measured on the friction torque test rig. Under combined loading, the expected correlations were achieved between the simulation and the test. Only in the case of purely axial loads does the tapered barrel roller bearing model underestimate the results measured in the test. Not least, the more extensive simulations show that when the loads are increased, the prototype has advantages over the comparative bearing in terms of frictional torque, as well as in terms of pressure for some of the load conditions under study. This could help to improve the lifetime of todays tapered bearing applications or, in other terms, the use of smaller bearings and its corresponding reduction of weight.

Further experimental investigations with the current optimization version, as well as a new optimization version designed more in the direction of radial bearings, are considered in further work in order to exploit the potential of this bearing design with regard to friction loss optimization.

\footnotetext{
Acknowledgements This work was carried out within the framework of the project "Model for the determination of thermal stresses in lubricants", which was financially supported by the German Research Foundation (DFG) e.V. This work was carried out within the framework of the project "Friction loss optimized rolling bearing for the substitution of highly loaded tapered roller bearings" (Project No. SA898/19-1).
}

\section{Funding DFG}

Funding Open Access funding enabled and organized by Projekt DEAL.

Conflict of interest M. Mármol Fernández, L. Rüth and B. Sauer declarethat they have no competing interests.

Open Access This article is licensed under a Creative Commons Attribution 4.0 International License, which permits use, sharing, adaptation, distribution and reproduction in any medium or format, as long as you give appropriate credit to the original author(s) and the source, provide a link to the Creative Commons licence, and indicate if changes were made. The images or other third party material in this article are included in the article's Creative Commons licence, unless indicated otherwise in a credit line to the material. If material is not included in the article's Creative Commons licence and your intended use is not permitted by statutory regulation or exceeds the permitted use, you will need to obtain permission directly from the copyright holder. To view a copy of this licence, visit http://creativecommons.org/licenses/by/4. $0 /$.

\section{References}

1. Bodenstein F, Haberhauer H (2005) Maschinenelemente. Springer, Berlin, Heidelberg, New York

2. Schaeffler Technologies GmbH (2021) Increase fuel mileage up to $2.5 \%$ with FAG tandem angular contact ball bearings in your final drive. https://www.schaeffler.com/remotemedien/media/_shared_ media/08_media_library/01_publications/schaeffler_2/brochure/ downloads_1/tsk_de_en.pdf. Accessed 13.01.2021

3. Wang D (2015) Berechnung der Wälzlagerreibung aufgrund weiterentwickelter Rheologischer Fluidmodelle. Diss., Universität Hannover

4. Jacob M, Jacob W (2008) Wälzlager; EP 2126388 B1, Date of filing: 11.02.2008

5. Kellström EM, Blomqvist LS (1973) Rollenlager, DE 2334394 C2, SKF Kugellagerfabriken GmbH, 8720 Schweinfurt, Date of filing: 06.07.1973

6. NTN Corporation Osaka-shi (2004) Double-row self-aligning roller bearing and device for supporting wind turbine generator main shaft; EP 1705392 B1, Date of filing: 16.11.2004

7. Kellström EM, Blomqvist LS (1976) Rollenlager, US 3990 753, SKF Industries Inc., King of Prussia, Pa., Date of filing: 27.02.1976

8. Aul V, Augustino R, Haehnel T, Vidner J, Sauer B, Gold P, Schlecht B, Leidich E (2007) MKS-Studie: Forschungsvereinigung Antriebstechnik. FVA-Heft, vol 8222

9. Sauer B, Kiekbusch T (2017) Dynamic simulation of the interaction between raceway and rib contact of cylindrical roller bearings. In: STLE Annual Meeting, Atlanta, USA (05.2017)

10. Kiekbusch T, Sauer B (2017) Calculation of the dynamic behaviour of rolling bearings with detailed contact calculations. In: Proceedings of the EUROMECH Colloquium 578 in Rolling Contact Mechanics for Multibody System Dynamics, Funchal, Madeira, Portugal (04.2017)

11. Kiekbusch T, Fruth T, Sauer B (2015) Analyse des dynamischen Verhaltens von Wälzlagern in WEA unter Berücksichtigung der Umgebungsverformung. In: 6. VDI-Fachtagung „Schwingungen von Windenergieanlagen“ Bremen (06.2015). VDI-Bericht, vol 2242, pp 83-96

12. Kiekbusch T (2017) Strategien zur dynamischen Simulation von Wälzlagern. Diss., TU Kaiserslautern

13. Teutsch R (2005) Kontaktmodelle und Strategien zur Simulation von Wälzlagern und Wälzführungen. Diss., TU Kaiserslautern 
14. Zhou RS, Hoeprich MR (1991) Torque of tapered roller bearings. J Tribol 113(3):590-597

15. Sebteini S, Hudak R, Sauer B, Jacobs G (2020) Mindestlast von Wälzlagern. Sachstandsbericht zum FVA-Vorhaben 830 I. In: Forschungsvereinigung Antriebstechnik e.V. (FVA), Webmeeting, Mai 2020

16. Liebrecht J, Si X, Sauer B, Schwarze H (2016) Technisch-mathematischer Ansatz zur Berechnung der Plansch- und Strömungsverluste am Kegelrollenlager. Tribol Schmierungstech 63(4):5-13

17. Liebrecht J (2018) Technisch-mathematischer Ansatz zur Berechnung der hydraulischen Verluste in Wälzlagern. Diss., TU Kaiserslautern
18. Kiekbusch T, Liebrecht J, Sauer B (2017) Dynamiksimulation von Wälzlagern unter Berücksichtigung der Plansch- und Schleppverluste. In: 12. VDI-Fachtagung Gleit- und Wälzlagerungen. 27.-28. Juni, 2017. Schweinfurt, pp 207-217

19. Marmol M, Kiekbusch T, Sauer B (2018) Friction losses optimized rolling bearing for substitution of highly loaded tapered rolling bearings. In: Bearing World Conference 2018-March 6-7, 2018, Kaiserslautern, Germany

20. Marmol M, Kiekbusch T, Sauer B (2018) Development of new rolling bearing for heavy-duty truck applications. In: Commercial Vehicle Technology 2018-March 13-15, 2018, Kaiserslautern, Germany 